\title{
Op-Ed
}

\section{The epidemic of pediatric obesity}

\section{Perspectives and approaches for primary care}

Thomas N Robinson
Division of General
Pediatrics and Center
for Research in
Disease Prevention
Stanford University
School of Medicine
1000 Welch Rd
Palo Alto, CA 94304
Correspondence to:
Dr Robinson
tom.robinson@stanford.
edu
Competing interests:
None declared
Funding: This work was
supported in part by
grants R01 HL54102,
R01 HL62224, and
U01 HL62663 from the
National Heart, Lung,
and Blood Institute,
Bethesda, MD; and a
Generalist Physician
Faculty Scholar Award
from the Robert Wood
Johnson Foundation,
Princeton, NJ
West J Med
2000;173:220-221

Pediatrics and Center

for Research in

Disease Prevention

Stanford University

School of Medicine

1000 Welch Rd

Correspondence to:

Dr Robinson

tom.robinson@stanford.

Competing interests: upported in part by

R01 HL62224, and

U01 HL62663 from the

National Heart, Lung,

and Blood Institute,

Bethesda, MD; and a

Generalist Physician

Faculty Scholar Award

from the Robert Wood

Johnson Foundation,

West J Med

2000;173:220-221
Most people do not need statistics to notice the fattening of our population, especially our children. In the United States across all ethnic groups and socioeconomic strata, the prevalence of pediatric obesity has doubled in the past 2 decades. ${ }^{1}$ Childhood obesity is both an immediate and future health problem. Sixty percent of overweight children already suffer from hypertension, hyperlipidemia, and/or hyperinsulinemia. ${ }^{2}$ Increased obesity has led to a new epidemic of type 2 diabetes mellitus in children and adolescents, ${ }^{3}$ and autopsy studies of children who died of traumatic causes show that early atherosclerotic lesions are already developing in the aortas and coronary arteries of overweight children. ${ }^{4}$

The first step for primary care physicians is to identify children at risk. The Centers for Disease Control and Prevention has recently released revised growth charts that are more representative of the US population and include body mass index (BMI) curves for boys and girls from age 2 to 20 years (http://www.cdc.gov/growthcharts/). The $\mathrm{BMI}$ is calculated as the weight in kilograms divided by the square of the height in meters: weight $(\mathrm{kg}) /[$ height $(\mathrm{m})]^{2}$. The BMI is the most appropriate measure to use in the clinical setting. ${ }^{5}$ Children above the 85 th percentile of the BMI growth curves should be considered at risk for overweight, and children above the 95th percentile should be considered overweight. Detailed recommendations for medical evaluation for overweight children are also available. ${ }^{6}$

Overweight children and adolescents are at significantly greater risk of adult obesity. Historical data suggest that the risk for adult overweight is primarily influenced by 2 factors. The first is age: overweight in 0 - to 5-yearolds is only minimally predictive of adult overweight; less than half of overweight prepubertal children have become overweight adults, whereas as many as $70 \%$ to $80 \%$ of overweight teens have become overweight adults. The second is parental overweight: children with overweight parents, regardless of child's weight, are at increased risk of becoming overweight adults. Overweight children at greatest need of treatment, therefore, are those who are already manifesting an obesity-associated morbidityhypertension, hyperlipidemia, hyperinsulinemia, diabetes, or poor self-esteem or depressive symptoms due to their weight — and those who are overweight beyond puberty, have 1 or more overweight parents, or both. ${ }^{7}$

Pediatric obesity treatments have been far from uniformly successful, although childhood treatment has produced better long-term results than adult treatment. The current state-of-the-art is intensive, family-based, group behavioral programs. In some studies, these programs have produced 10-year success in up to $30 \%$ of children. ${ }^{8}$ Unfortunately, state-of-the-art group programs are not available in most communities, but they have features that can be adopted by clinicians. ${ }^{9}$ These include involving parents_-and other family members - in treatment, allowing changes in the home environment and social support for these changes instead of policing; scheduling frequent visits to provide timely feedback; considering treatment as a long-term process (most overweight develops over years and may require years to treat); and using proven behavioral change strategies, self-monitoring, achievable but challenging short-term and long-term goals, feedback, and contracting and rewards to encourage achieving these goals. Parental skills training can also be effective. Parents are taught to be contingent and consistent and to avoid giving mixed messages and reinforcing undesired behaviors. They are also taught to be observant of their children's behaviors so they can reward them when appropriate, to direct their praise at children's behaviors instead of their personal attributes, to model desired behaviors, to deal with setbacks, to have patience for changes in behavior, and to set limits—saying "no" when necessary. ${ }^{9}$

All excess weight, regardless of the underlying cause, results from excess calorie consumption over calorie expenditure. Therefore, the key element of any behavioral treatment boils down to sustained changes in diet, activity, or both. The most successful goals for diet and activity change are simple and explicit. For example, "eat fewer high-fat foods" and "do more exercise" are not useful behavioral goals compared with "switch from whole milk to fat-free milk," "replace soft drinks and juice drinks with water," "remove cookies and cakes from the home," "walk to school instead of driving at least 3 days per week," or "limit television viewing to 1 hour per day." A brief dietand-activity history can elicit appropriate behaviors to target, and simple and explicit goals are necessary for selfmonitoring, feedback, and rewards.

To complement the treatment of children who are already overweight, primary care physicians also can promote primary prevention. Little research has been done on obesity prevention in clinical settings, but the same behavioral techniques used in treatment apply. Children with an overweight parent should be especially targeted, although a calorie-balanced diet and increased physical activity are appropriate for almost all children and families, regardless of their risk for obesity.

Substantial attention has gone into public health approaches to prevention. These are community programs 
that target all children. Because of the number of people involved, small improvements in the population as a whole can produce even greater reductions in morbidity and mortality than effective treatment interventions involving only high-risk patients. Like treatments, however, these public health interventions are not always successful. Traditional school and community health education approaches have produced few benefits in body weight, but a handful of behaviorally based programs have proved successful. Examples include a school-based self-directed behavior change program for adolescents ${ }^{10}$; substituting popular dance or vigorous endurance training for regular physical education for middle-school students ${ }^{11,12}$; and a curriculum to reduce television, videotape, and video game use in elementary school children. ${ }^{13}$ If more successful programs like these can be developed and disseminated, population-based prevention may hold the greatest promise for addressing the epidemic of pediatric obesity. Primary care providers can be effective advocates for the adoption of evidence-based public health programs in their local schools and communities, while also providing counseling and therapy for their overweight patients and families.

References

1 Troiano RP, Flegal KM, Kuczmarski RJ, Campbell SM, Johnson CL. Overweight prevalence and trends for children and adolescents: the
National Health and Nutrition Examination Surveys, 1963 to 1991. Arch Pediatr Adolesc Med 1995;149:1085-1091.

2 Freedman DS, Dietz WH, Srinivasan SR, Berenson GS. The relation of overweight to cardiovascular risk factors among children and adolescents: the Bogalusa Heart Study. Pediatrics 1999;103:11751182.

3 Pinhas-Hamiel O, Dolan LM, Daniels SR, Standiford D, Khoury PR, Zeitler P. Increased incidence of non-insulin dependent diabetes mellitus among adolescents. J Pediatr 1996;128:608-615.

4 Berenson GS, Srinivasan SR, Bao W, et al. Association between multiple cardiovascular risk factors and atherosclerosis in children and young adults. $N$ Engl J Med 1998;338:1650-1656.

5 Dietz WH, Robinson TN. Use of the body mass index (BMI) as a measure of overweight in children and adolescents. J Pediatr 1998;132:191-193.

6 Barlow SE, Dietz WH. Obesity evaluation and treatment: expert committee recommendations. Pediatrics [serial online] 1998;102:e29. Available at: http://www.pediatrics.org/cgi/content/full/102/3/e29. Accessed August 2, 2000.

7 Robinson TN. Defining obesity in children and adolescents: clinical approaches. Crit Rev Food Sci Nutr 1993;33:313-320.

8 Epstein LH, Valoski A, Wing RR, McCurley J. Ten-year outcomes of behavioral family-based treatment for childhood obesity. Health Psychol 1994;13:373-383.

9 Robinson TN. Behavioural treatment of childhood and adolescent obesity. Int J Obes Relat Metab Disord 1999;23(suppl 2):S52-S57.

10 Killen JD, Telch MJ, Robinson TN, Maccoby N, Taylor CB, Farquhar JW. Cardiovascular disease risk reduction for tenth graders. JAMA 1988;260:1728-1733

11 Flores R. Dance for health: improving fitness in African American and Hispanic adolescents. Public Health Rep 1995;110:189-193.

12 Dwyer T, Coonan WE, Leitch DR, Hetzel BS, Baghurst RA. An investigation of the effects of daily physical activity on the health of primary school students in South Australia. Int J Epidemiol 1983;12:308-313.

13 Robinson TN. Reducing children's television viewing to prevent obesity: a randomized controlled trial. JAMA 1999;282:1561-1567. 
tion, after a long moratorium, decided that these ads required no new regulation beyond the "fair balance provision" of the 1962 Kefauver-Harris amendments, which requires that manufacturers truthfully present a fair balance of risks-side effects and contraindications - and effectiveness. Expenditure for this advertising currently comprises $15 \%$ to $20 \%$ of total drug marketing costs and is projected to increase to $\$ 7.5$ billion by 2005 .

The arguments for and against direct-to-consumer advertising are already becoming a little tiresome, even to one who has been actively engaged in the debate. ${ }^{1,2}$ In general, proponents claim that "by greatly increasing the likelihood that patients will seek help for their medical problems and receive a safe and effective prescribed medicine, DTC advertising will ... play a very real role in enhancing public health."3

Critics counter that

extending the scope of already ubiquitous promotions about "post-nasal drip," "unsightly rashes," or "cures" for baldness has little to do with educating patients or relieving suffering. It will, however, inevitably drain healthcare dollars, dramatically increase unnecessary prescribing, and strain patient-doctor relationships. ${ }^{4}$

With nothing less than the health of the public at stake, not to mention billions of dollars, it is no wonder that the debate has veered toward acrimony. Each side has tended to overstate its case. Yes, these ads may prompt some patients to seek care for previously undiagnosed and untreated conditions. And, yes, they may spur other patients to make unnecessary visits to the doctor and to incur the risk of medication side effects while gaining little benefit. However, the net benefits and risks of direct-to-consumer

\section{Drug manufacturers should do more}

\section{educating and less selling}

promotion are unknown. The research required to make these assessments is difficult.

The net public health gain or loss of this advertising will be determined by 3 things: the current prevalence of undertreatment (the number of patients not receiving drug therapy who should be), the amount of inappropriate or harmful prescribing that might be stimulated by such ads, and the degree of harm accruing to undertreated compared with overtreated patients. Until substantial resources are allocated to this research agenda, we will not know which side is right. In practical terms, however, it may not matter. Direct-to-consumer advertising is here to stay. The real question is how it should be delivered so as to maximize the benefits while minimizing potential harms.

Here is my prescription. Drug manufacturers should do more educating and less selling. This means focusing on conditions rather than drugs; assisting patients with home-based triage and self-care; presenting information on treatment alternatives, including nonpharmacologic therapies; helping patients who decide on medication to optimize adherence; and promoting partnerships with physicians. As an example of partnership, drug firms should alert physicians before launching direct-toconsumer ad campaigns and help them prepare for ques-

\section{The true net benefits and risks of}

\section{direct-to-consumer promotion are}

\section{unknown}

tions their patients are likely to ask. Government should, in the words of an American College of Physicians' position paper, "impose serious limits on the pharmaceutical industry to ensure that consumers receive complete and nonconfusing information." 5 The FDA's current policy of retrospective review is inadequate. Government should also fund research to ensure that in 5 years we will know more about the true benefits and risks of this advertising. The medical profession should partner with government, foundations, and the news media to create sources of objective consumer drug information, such as a "Medical Letter" to consumers, and public service announcements alerting consumers of undertreated conditions, like depression and hyperlipidemia. In the meantime, physicians should brace themselves for growing hordes of patients bearing ads.

References

1 Bell RA, Kravitz RL, Wilkes MS. Direct-to-consumer prescription drug advertising and the public. J Gen Intern Med 1999;14:651-657.

2 Wilkes MS, Bell RA, Kravitz RL. Direct-to-consumer prescription drug advertising: trends, impact, and implications. Health Aff (Millwood) 2000;19:110-128.

3 Holmer AF. Direct-to-consumer prescription drug advertising builds bridges between patients and physicians. JAMA 1999;281:380-382.

4 Hoffman JR, Wilkes MS. Direct to consumer advertising of prescription drugs: an idea whose time should not come [editorial]. BMJ 1999;318:1301-1302.

5 American College of Physicians-American Society of Internal Medicine. Governmental affairs and public policy: direct to consumer advertising for prescription drugs. October 9, 1998. Available at: http:// www.acponline.org/hpp/pospaper/dtcads.htm. Accessed July 25, 2000. 


\title{
Guidelines for managing acute bacterial meningitis in adults
}

\author{
Speed in diagnosis and treatment is essential
}

Nearly 1 in 4 adults with acute bacterial meningitis die, and many survivors sustain neurologic deficits. ${ }^{1,2}$ The outcome has not changed since the early 1960s despite the introduction of potent antibiotics and specialized intensive care units. ${ }^{3}$ Can anything further be done to optimize treatment and improve outcome?

The prognosis is worse with a delay in management. ${ }^{4}$ Consequently, the outcome depends on whether the attending physician suspects acute bacterial meningitis and whether the health care system is set up to make a rapid, accurate diagnosis and initiate fast and effective treatment.

In this respect, standardized guidelines such as those recently issued by the working party of the British Infection Society are invaluable. ${ }^{5}$ These guidelines make recommendations for the management of adults with suspected or diagnosed acute bacterial meningitis or meningococcal disease and for the prevention of secondary cases by vaccination and prophylactic antibiotic treatment. The guidelines may provide a template for treating acute bacterial meningitis for physicians in most countries. However, countries that now vaccinate against Haemophilus influenzae type $\mathrm{b}$ or meningococci serogroup $\mathrm{C}$ may see $\mathrm{a}$ change in the epidemiologic characteristics of bacterial meningitis.

There is little evidence on the best way to manage patients as soon as they present with acute bacterial meningitis. The new report advises family physicians to give benzylpenicillin (penicillin $G$ ) to any patients who may have acute bacterial meningitis before they are admitted to the hospital. With elderly patients, however, more caution may be needed. First, the outcome from acute bacterial meningitis has not been shown to be improved by the preadmission use of antibiotics; the crucial factor is probably whether the attending physician suspects acute bacterial meningitis at all and therefore arranges immediate admission to a hospital. Second, preadmission antibiotic use may make it harder to get a definitive microbial diagnosis.

For a young patient with suspected meningococcal disease, the immediate use of antibiotics, followed by rapid admission to a hospital, may be the best course of action. In patients with suspected bacterial meningitis of other causes, arranging rapid transfer to a hospital, followed by speedy microbiologic testing and antibiotic treatment, may be more prudent. After admission to the hospital, the widely accepted empiric treatment is the administration of a third-generation cephalosporin, such as cefotaxime sodium or ceftriaxone sodium, with ampicillin if listerial meningitis cannot be ruled out. In patients with obvious meningococcal disease, penicillin is the drug of choice.

The reduced susceptibility of pneumococci to penicillin is an increasing problem in large parts of the world; this may often be overcome by increasing the amount and frequency of doses, but rifampicin (rifampin) may be useful for pneumococci that are truly penicillin-resistant. ${ }^{6}$ Selecting the appropriate therapy for patients with acute bacterial meningitis who are hypersensitive to $\beta$ lactams is difficult. Chloramphenicol is not ideal because of its low clinical efficacy and potential side effects; meropenem or broad-spectrum quinolones may be considered, although there is little evidence that they work.

Supportive treatment has been hotly debated. Corticosteroids reduce neurologic deficits in children with $H$ influenzae meningitis, whereas their beneficial effect in adults remains to be proved. ${ }^{7}$ It is hoped that the results of the multicenter European trial on dexamethasone use in acute bacterial meningitis, scheduled to end in a year, will provide conclusive evidence. The use of glycerol or mannitol may reduce intracranial pressure when there is intracranial hypertension. ${ }^{8}$ The need for full fluid replacement and maintenance is rightfully emphasized in the guidelines. Fluid restriction does not lessen brain edema or improve outcome in patients with acute bacterial meningitis. ${ }^{9,10}$ Furthermore, cerebral perfusion depends on the mean arterial blood pressure in these patients and is adversely affected by hypovolemia. ${ }^{11}$ Also, these patients are at risk of sepsis with hypotension. In general, many patients with acute bacterial meningitis need intensive care to monitor and treat both cerebral and extracerebral complications.

The guidelines are the laudable result of a major effort from the working party and should be disseminated to all physicians. An increased awareness of acute bacterial meningitis with emphasis on speedy diagnosis and treatment will serve patients well.

References

1 Pfister HW, Feiden W, Einhäupl KM. Spectrum of complications during bacterial meningitis in adults: results of a prospective clinical study. Arch Neurol 1993;50:575-581.
Kirsten Møller

Research Fellow Peter Skinhøj

Professor

Department of Infectious Diseases 5132

University Hospital Rigshospitalet Copenhagen, Denmark

Correspondence to: Dr Møller

kirsten.moller@ dadlnet.dk

Competing interests: None declared

This editorial was previously published in BMJ 2000;320:1290 
2 Bohr V, Hansen B, Kjersem H, et al. Sequelae from bacterial meningitis and their relation to the clinical condition during acute illness, based on 667 questionnaire returns: part II of a three part series. J Infect 1983;7:102-110.

3 Durand ML, Calderwood SB, Weber DJ, et al. Acute bacterial meningitis in adults: a review of 493 episodes. $N$ Engl J Med 1993;328:21-28.

4 Aronin SI, Peduzzi P, Quagliarello VJ. Community-acquired bacterial meningitis: risk stratification for adverse clinical outcome and effect of antibiotic timing. Ann Intern Med 1998;129:862-869.

5 Begg N, Cartwright KAV, Cohen J, et al. Consensus statement on diagnosis, investigation, treatment and prevention of acute bacteria meningitis in immunocompetent adults: British Infection Society Working Party. I Infect 1999;39:1-15.

6 Reacher MH, Shah A, Livermore DM, et al. Bacteraemia and antibiotic resistance of its pathogens reported in England and Wales between 1990 and 1998: trend analysis. BMJ 2000;320:213-216.
7 Lebel MH, Freij BJ, Syrogiannopoulos GA, et al. Dexamethasone therapy for bacterial meningitis: results of two double-blind, placebo-controlled trials. $N$ Engl J Med 1988;319:964-971.

8 Kilpi T, Peltola H, Jauhiainen T, Kallio MJ. Oral glycerol and intravenous dexamethasone in preventing neurologic and audiologic sequelae of childhood bacterial meningitis: the Finnish Study Group. Pediatr Infect Dis J 1995;14:270-278.

9 Täuber MG, Sande E, Fournier MA, Tureen JH, Sande MA. Fluid administration, brain edema, and cerebrospinal fluid lactate and glucose concentrations in experimental Escherichia coli meningitis. J Infect Dis 1993; 168:473-476.

10 Singhi SC, Singhi PD, Srinivas B, et al. Fluid restriction does not improve the outcome of acute meningitis. Pediatr Infect Dis J 1995; $14: 495-503$

11 Møller K, Larsen FS, Qvist J, et al. Dependency of cerebral blood flow on mean arterial pressure in patients with acute bacterial meningitis. Crit Care Med 2000;28:1027-1032.

\section{A book that made me think}

Bioethics: An Anthology, Helga Kuhse, Peter Singer, eds. Blackwell Publishers, \$39.95, pp 600, ISBN 0631 203117

Peter Singer was a keynote speaker at the last annual meeting of the American Society of Bioethics and Humanities in Philadelphia. For various reasons, I had chosen this moment in the program to duck out of the conference. I was completely unprepared for what greeted me as I left the hotel-protesters, many confined to wheelchairs, chanting "Less debate, more hate." This, I discovered, was the disability activist group Not Dead Yet, which is incensed about Singer's stance that some people with disabilities are not "persons" and may be killed or allowed to die with impunity. It is rare for philosophers to incite the ire of the community at large. Socrates and Bertrand Russell did, and now it seems Peter Singer has joined the ranks of infamy.

I am disappointed by Kuhse and Singer's edited collection of philosophical papers on bioethics. The selection is deeply conservative, and it eschews literature at the margins of bioethics. This is a shame because contemplation of narrative ethics, anthropology, families, and communities is where the action has been in bioethics during the past decade. My attention was naturally drawn to the four essays by Singer himself in the volume. Here, I was not disappointed but offended. Singer variously concluded that experimenting on a human embryo is preferable to doing so on a mouse; that chimpanzees are properly called "people," but humans with profound cognitive impairments are not; and that the heart of a handicapped newborn human might be legitimately excised to save a baboon in need of a new heart. Some have argued that Singer is not responsible for these absurd conclusions since he is merely working through the logical outcomes of a particular moral theory, utilitarianism. Whatever faults we may find with the outcome are properly attributed to the theory and not the philosopher. I disagree: Singer is culpable for these views because doing ethics responsibly involves more than logical reasoning alone. Moral intuition acts as an important check on ethical reasoning, telling us that at times it is the theory, not our actions, that must be changed. More than once Singer notes, "At first this sounds crazy," and more than once he fails for not paying attention to his own intuition.

My reaction to Singer's work is akin to discovering that a friend has served me her pet for dinner. As my initial reaction of disgust fades, I would wonder whether the animal was really a pet, and, if it was, whether my friend actually understands what it means to have a pet. Having a pet implies a set of rules describing the proper relationship between owner and pet and not eating one's pet is high on the list. The terms "person" and "animal" come with their own sets of rules, embedded deep within our society, defining relationships among human beings and between people and animals. Singer, in suggesting that these terms or the rules associated with them may be interchangeable, demonstrates that he fails to understand the concepts of "person" and "animal" at all.

Charles Weijer, bioethicist

Dalhousie University, Halifax, Canada

This review first appeared in the $B M J$ 2000;320:1215 